\title{
"Trust but verify"? The performance implications of verification strategies in trusting relationships
}

\author{
Gregory T. Gundlach • Joseph P. Cannon
}

Received: 28 June 2006 / Accepted: 29 October 2009

(C) Academy of Marketing Science 2009

\begin{abstract}
Considerable extant research demonstrates the benefits of trust in buyer-seller relationships. More recent research points out downsides of the vulnerability inherent with trust. Recognizing this dilemma of trust, partners may offset the vulnerability of trust with verification strategiesefforts to produce information relevant to the exchange relationship. This research examines the use of three types of verification strategies-monitoring, assurances, and corroboration-which may be employed to safeguard against the vulnerability of trust. When control mechanisms like trust and information are combined, they may complement one another and enhance performance or function as substitutes, be redundant or compete, and consequently detract from performance. Emerging theory on combined modes of governance provides insights. We draw on this theory and develop hypotheses proposing that combinations of trust and verification may enhance or
\end{abstract}

Gregory T. Gundlach is Coggin Distinguished Professor in Marketing at the University of North Florida. Joseph P. Cannon is Associate

Professor of Marketing at Colorado State University. The authors have contributed equally to this project and the order of authorship is random. The authors appreciate support from the National Association of Purchasing Management and the Purchasing Management Association of the Carolinas and Virginia. The authors appreciate comments from Kevin Bradford and Dave Gilliland on an earlier version of this manuscript.

G. T. Gundlach $(\bowtie)$

University of North Florida,

Jacksonville, FL, USA

e-mail: ggundlac@unf.edu

\section{J. P. Cannon}

Colorado State University,

Fort Collins, CO, USA

e-mail: Joe.Cannon@business.colostate.edu detract exchange performance-depending on the specific verification strategy. The hypotheses are tested on a sample of 230 buyer-supplier relationships. Results of the research provide some support for the proposed relationships and yield implications for the management of cooperative exchange relationships.

Keywords Trust · Information · Performance · Distribution . Exchange - Governance

In the past two decades both scholars and practitioners have increased attention on the performance implications of cooperative exchange relationships brought about and managed through various mechanisms including trust. Participants in exchange who trust one another reportedly may obtain a variety of performance related benefits including: (1) eliminated duplication of activities (Scanzoni 1979), (2) system and transaction savings (Ouchi 1980; Dore 1983; Noordewier et al. 1990; Sako 1992), (3) enhanced adaptability (Zand 1972), (4) lower opportunism (Rindfleisch and Moorman 2003); (5) greater commitment, cooperation, collaboration, interaction, integrative bargaining, loyalty (and less propensity to switch), relationalism, satisfaction, and anticipated long-term interaction (Agustin and Singh 2005; Anderson and Weitz 1989; Cannon and Perreault 1999; Chiou and Droge 2006; Doney and Cannon 1997; Ganesan 1994; Grayson et al. 2008; Jap and Anderson 2003; Morgan and Hunt 1994; Palmatier et al. 2008), (6) a greater willingness to explore opportunities and implement decisions (Golembiewski and McConkie 1975), (7) a share of a customer's purchases (Ahearne et al. 2007), service usage (Maltz and Kohli 1996) and sales performance overall (Palmatier et al. 2008). Together, this and other research suggests that trust can enhance relationship quality and facilitate performance in exchange. 
At the same time, some scholars have begun to question the trust-performance linkage. Citing the failure rate of many "close" and trusting exchange relationships, Anderson and Jap (2005) report on what they and others (Grayson and Ambler 1999) refer to as the "dark side of close relationships" or the anomaly that "close relationships [involving trust] that seem the most stable can also be the most vulnerable to decline and destruction" (p. 75). For example, in highly trusting relationships, partners may hold back negative or critical information-limiting opportunities for learning how to enhance performance (Selnes and Sallis 2003). After reviewing a diverse set of literature, AtuaheneGima and Li (2002) warn there is insufficient empirical evidence to support the positive relationship between trust and performance and warn "trust may be in danger of being 'oversold' and inappropriately used in practice" (p. 61).

In many exchange relationships, certain forms of malfeasance are only possible where trust allows the opportunity for advantage taking. Atuahene-Gima and Li (2002, p. 62) note that "...trust carries a risk of betrayal, [and] may lead to illegal and immoral pursuits...". At the extreme, trust provides the sine qua non circumstance upon which many forms of extreme misconduct rely (e.g., embezzlement, some types of telemarketing fraud, Ponzi schemes, and insider trading). Kramer (2009) suggests that while trusting others served humanity in evolution, this readiness to trust makes humans likely to make mistakes when conferring trust. Consequently we trust too much and often become victims of unscrupulous behavior. ${ }^{1}$ More common to many marketing exchanges, however, are circumstances involving less reprehensible forms of misconduct and advantage seeking that nevertheless may still affect performance in a relationship. For example, while a customer firm may trust one of its suppliers, the supplier may take advantage of that trust and shirk on promises to deliver product on time, provide quality that meets expectations, charge "market" prices, or keep agreed upon service obligations. In each case, the party's violation of the other's trust can lead to adverse outcomes that lower desired exchange performance.

In search of an explanation for the divergence of findings relating to trusting or close relationships and performance some scholars speculate that trust may play a dual role in commercial exchange. While trust may both enable and empower a relationship to achieve beneficial outcomes, trust also creates conditions of vulnerability that increase the ability of a supplier to act opportunistically or engage in other actions that undermine performance. More specific reviews of the literature on trust reveal that scholars in various fields have long described what may be called the dilemma of trust - the quandary that together with its

\footnotetext{
${ }^{1}$ The Madoff Ponzi scheme uncovered in 2008 relied on customers' trust of Bernard Madoff.
}

positive benefits, trust entails vulnerability and potential adverse outcomes in the event that a trusted partner takes advantage of misplaced trust (Atuahene-Gima and Li 2002; Deutsch 1958; Hamel 1991; Kramer et al. 1996; Kramer 2009; Luhmann 1979; Zand 1972).

Given the dilemma of trust, what should a party to an exchange relationship do to help obtain the benefits of trust while safeguarding against its potential challenges? We propose that firms in exchange relationships produce information about a partner's performance and intentions (Mayer et al. 1995; Rose 1995). The information based approach is captured in the well-known phrase "trust but verify"-which reflects trusting exchange partners' attempts to address the vulnerabilities inherent in trust by producing relevant information. Literature across a wide range of disciplines suggests at least three verification strategies may be used to safeguard commercial exchange in this fashion: (1) monitoring a supplier's outputs, (2) openly sharing information, or (3) actively monitoring the supply market, including current and potential suppliers, for information (Abbott 1993; Rose 1995; Heide et al. 2007; Ittner et al. 1999; Merchant 1990).

While each of these three verification strategies has a direct effect on a supplier's performance, our primary focus is to understand how each strategy (together with the information it yields) operates in combination with trustor a lack of trust. Theory suggests two approaches when governance modes are combined. The substitution view (Williamson 1991; Granovetter 1985) dominates governance thinking and proposes that multiple control mechanisms are redundant and therefore inefficient. The higher transaction costs of multiple governance mechanisms result in lower performance. For example, in transaction cost economics, market governance is preferred unless an exchange involves a high level of asset specificity - at which point the market fails and a hierarchical solution of vertical integration or detailed contracts (Stinchcombe 1985) becomes the optimal governance choice (Williamson 1985). The complementarity perspective contends that governance may be crafted with multiple mechanisms that address different governance problems and complement or reinforce one another and offer superior control (Heide et al. 2007; Lazzarini et al. 2004). The latter perspective typically considers a broader set of performance outcomes, emphasizing effectiveness in addition to traditional efficiency concerns.

Extant research finds support for both the substitution and complementarity views - some combinations of governance operate to enhance performance while other combinations detract from performance. For example, formal modes of governance and overt monitoring may signal distrust and encourage shirking on performance, and shirking may be more possible when an exchange partner is more trusted (Ghoshal and Moran 1996; Macaulay 1963). 
One explanation for the deterioration in performance is that formal modes of governance "crowd out" the benefits of social norms inherent in trusting relationships (Frey 1997; Wang et al. 2008). On the other hand, some combinations complement each other to enhance performance (Lazzarini et al. 2004). Poppo and Zenger (2002) suggest that relational governance reduces risk, enhances commitment, and fills in governance gaps not adequately protected by contracts-operating in combination to enhance performance. Drawing on these theories and prior empirical research, we hypothesize the beneficial and detrimental effects on performance when trust combines with different modes of information production. Trust but verify?maybe, but it depends on the verification strategy.

Thus, we contribute to the literature on exchange and governance by: (1) describing the dilemma and duality of trust and how they generate a need for verification, (2) showing how verification strategies may combine with trust to enhance or detract from a supplier's performance, and (3) extending emerging research on the use of multiple forms governance within specific relationships (Bradach and Eccles 1989; Cannon et al. 2000). We begin by explaining the dilemma of trust, and how this dilemma influences trust and performance in relationships. Next, we develop the rationale for a series of hypotheses predicting how trust and verification affect performance. We then describe an empirical study which tests these predictions across a sample of 230 buyer-supplier relationships. The results of the study provide support for a number of the predicted relationships. Each is discussed with implications for research and practice advanced.

\section{Trust and performance in exchange: the dilemma of trust}

The vast literature on trust conceptualizes it in various ways, including calculative assessments of the various qualities held by a trusted partner that reflect the partner's trustworthiness. Such qualities include the partner's reliability, integrity, honesty, credibility and benevolence, among others. Morgan and Hunt (1994, p. 23), for example, define trust "as existing when one party has confidence in the exchange partner's reliability and integrity." Drawing on prior work addressing interfirm and group relationships (Ganesan 1994; Kumar et al. 1995), Doney and Cannon (1997, p. 37) define trust as the "perceived credibility and benevolence of a target of trust." Similarly, others (e.g., Geyskens et al. 1998; Grayson et al. 2008) define trust as a belief that an exchange partner is benevolent and honest. Conceptions of trust common to both the interfirm and interpersonal domains capture the widely held view that trust involves the willingness to rely upon another, which has as its basis an expectation that the motives, intentions and behavior of the trusted partner are worthy of one's trust (i.e., they are trustworthy) (Blois 1999). Defined in this fashion, trust may be viewed as existing along a continuum with higher levels of trust exhibited through stronger views as to the trustworthiness of an individual or institution, based upon calculations of their relevant motives, intentions and behaviors.

\section{Trust and performance}

Extensive interest in trust within marketing has in part been motivated by the widely held view that trust plays an important and positive role in the performance of ongoing exchange relationships. Performance in this context includes outcomes considered important in the relationship and compared to what might be obtainable in other relationships. In the buyer-seller context such attributes include among others the level of product quality provided, delivery performance, provision of service or technical support, and assessments of the total value received (Lehmann and O'Shaugnessy 1974; Wilson 1994).

At least a modest level of trust exists in all modern commercial relationships (Ring and Van de Ven 1992). Yet higher levels of trust provide more general benefits to exchange- acting as an "extremely efficient lubricant" for exchange (Lorenz 1988, p. 198). Similarly, Luhmann (1988, p. 95) suggests that trust provides "a solution for specific problems of risk" that may arise in exchange.

Within marketing and its related disciplines, scholars studying interfirm relationships theorize that the confidence and expectation building qualities of trust nurture more effective interaction and supportive performance within cooperative exchange, while trusting behavior itself can help to reduce transaction costs and foster more efficient interaction. A buyer's trust that a supplier will perform, for example, is thought to yield efficiencies through mitigating transaction costs that would otherwise occur in the absence of trust (Noordewier et al. 1990; Sako 1992). More effective performance is also thought to result given the positive effects of the buyer's enhanced confidence in the seller's performance and through the added value obtained from expectations regarding the seller's benevolence (Anderson and Weitz 1989; Ganesan 1994; Morgan and Hunt 1994). Some researchers also believe that trust may impact performance in such relationships by serving as a substitute for more formal mechanisms of governance (Rindfleisch and Heide 1997) or alternately as a form of governance in its own right (Bradach and Eccles 1989; Gundlach 1994).

Yet the strong normative bias in favor of trust has been called into question (Anderson and Jap 2005; Grayson and Ambler 1999). Atuahene-Gima and Li (2002) point out that 
studies conducted across a variety of contexts within marketing (i.e., interpersonal, intergroup, interfirm, etc.) find that trust only modestly predicts performance (Smith and Barclay 1997), both positively and negatively affects performance depending on the context (Dahlstrom and Nygaard 1995) or is unrelated to performance (Crosby et al. 1990; Doney and Cannon 1997; Aulakh et al. 1996). Other marketing scholars raise questions about opportunism and the potential for shirking or opportunism in highly trusting and close relationships (Anderson and Jap 2005; Selnes and Sallis 2003). Other reviews (Dirks 1999) raise similar questions.

The dilemma of trust One explanation advanced for the divergence of empirical findings describing the relationship of trust and performance is what may be called the dilemma of trust - the recognition that by granting trust in an exchange, one may reap benefits but also be vulnerable to an opportunistic partner. For trust to be conceptually relevant in exchange, there must be an actual possibility of loss (Gambetta 1988). Conferring trust involves the regulation of one's dependence in such a way as to actually increase one's vulnerability to the actions of another whose behavior one cannot control (Zand 1972; Deutsch 1962). This vulnerability opens the trusting party to potential harm (Kramer 2009).

The dual potential of trust for performance has also been identified as one reason why some cooperative exchange relationships fail and many that seem stable are often vulnerable to destruction and decline. Analyzing a number of failed relationships, Anderson and Jap (2005) find, for example, that while trust helped manage the relationships more efficiently, it ultimately provided the opportunity for trusted suppliers to "systematically cheat their clients on an ongoing basis" (p. 76). ${ }^{2}$ Ironically, trust provided the pathway to a darker side of buyer-supplier relationships (Grayson and Ambler 1999). The duality of trust as a lubricant, making relationships more efficient, also creates vulnerability and a potential road to opportunism and lower performance.

\section{The performance implications of trust and verification strategies in buyer-supplier relationships}

The dilemma of trust provides an important basis and motivation for investigating the managerial arrange-

\footnotetext{
$\overline{2}$ These factors are further exacerbated given that as found by these researchers, "partners also remain surprisingly loyal within business relationships... dealers who believe their trusted supplier has abused them often react with resignation, silence and even loyalty" (Anderson and Jap 2005, p. 76).
}

ments adopted by exchanging parties in trusting relationships and the implications of such arrangements for performance. The inherent weaknesses and vulnerabilities of trust as a governance mechanism suggest it may be supplemented by other mechanisms (Gambetta 1988). Others have also called for the investigation of these arrangements. Geyskens et al. (1998, p. 245), for example, urge researchers to "explore more complex interactive patterns relating to trust." Relatedly, Moorman et al. (1993, p. 94) counsel that "how trust operates in conjunction with other relationship factors such as ... controls warrants greater research attention."

One avenue for supplementing the mechanism of trust and its inherent vulnerability may be through the production of information relevant to the relationship and exchange. As pointed out by Mayer et al. (1995) and others (Atuahene-Gima and Li 2002, p. 62), among other factors "the risks inherent in trust arise ... because there is incomplete information about other people's intentions." Rose (1995, p. 535) and others (see Lewis and Weigert 1985), point out that in economic exchange, trust "asks for assurances and monitoring."

Theories from economics of information provide insights for understanding how information may be produced to address the dilemma of trust. Information of particular relevance in trusting relationships includes knowledge about the performance capabilities of the other party, information regarding the other party's intended behavior and information from third parties concerning the trusted party. Marketing scholars have also emphasized the role of information production to address exchange vulnerability (Aiken and Boush 2006; Bergen et al. 1992; Heide et al. 2007; Rao and Monroe 1996). In these circumstances, information supplements and fills in gaps created by trust (cf. Blois 1999).

\section{Verification efforts in trusting relationships}

The literature on information economics starts with the assumption that exchange participants often possess information in differing amounts, leading to asymmetries of information. Such situations create uncertainty and other problems in the performance of an exchange (e.g., adverse selection, moral hazard, etc.). A disadvantaged exchange partner may respond to this asymmetry and vulnerability by producing information relevant to the exchange. These observations have been made in marketing and other literature (Bergen et al. 1992; Lippman and McCall 2001; Rose 1995). A key contribution of the information economics literature is the description of how participants solve these problems with information. Signaling theory describes how an exchange participant may affirmatively share with others informa- 
tion about themselves (i.e., signal) in an effort to resolve uncertainty stemming from asymmetries of information (Spence 1973). And screening theory explains how a participant may attempt to collect information about an exchange partner (i.e., screen) to rectify this uncertainty (Spence 1973).

Beyond the foundational insights derived from information economics, other theories also address the production of information in exchange-and information's role in governance and control. This includes work that examines: (1) the information based command and control strategies associated with a specific form of governance arising from transaction cost and agency theory, (2) the information related dimensions of governance found in relational exchange theory, and (3) the information based communication strategies characterizing power exercise in dependent relationships found in resource dependence theory. In the case of transaction cost theory, for example, applications in marketing teach that verification efforts are commonly associated with market based governance (Heide and John 1990) where monitoring accompanies hierarchical structures (Gilliland and Bello 1997; Celly and Frazier 1996; Stump and Heide 1996; Wathne and Heide 2000) and information disclosure is found in the context of hybrid forms (Macneil 1980; Williamson 1985, 1991). Similar insights arise from agency theory, which contemplates control strategies in the context of alternative principle-agent contracts. In particular, behavior-based contracts rely on monitoring while outcome-based contracts emphasize verification to achieve control (Jensen and Meckling 1979). Relational exchange theory on the other hand contemplates information sharing as one of 28 overlapping norms which define relational exchanges (Macneil 1980). Finally, considerable work on resource dependence emphasizes the differing communication (including information) strategies which distinguish the nature of power exercise in interdependent relations (Frazier and Sheth 1985; Frazier and Summers 1984; Mohr et al. 1996).

As to more specific understanding of the nature of information strategies found in trusting relationships, scholarship in international relations provides insights that explicitly contemplate strategic interactions involving trust. $^{3}$ Included in this literature are references to strategies for the production of information captured under the

\footnotetext{
${ }^{3}$ The international relations literature has relevance for the study of marketing exchange relationships given it addresses "strategic situations ... involving a relationship of interdependence among a relatively small number of actors" (Abbott 1993, footnote 4). Many exchange relationships involve such circumstances, e.g., marketing channel, buyer-seller.
}

popular phrase "trust but verify" (Abbot 1993). ${ }^{4}$ Differentiated by their strategic orientation and locus of implementation, three information (i.e., verification) strategies are identified: monitoring, assurance and corroboration (Abbott 1993; Snidal 1985; Stein 1982). Table 1 describes these information production strategies in the context of marketing exchanges. In this respect, and paralleling conceptions in information economics, verification of one's trust in an exchange partner may be conducted, for example, through observing the partner in an effort to evaluate their capabilities and motives (i.e., monitoring), gaining the assurance of the partner's capabilities and motives through mutual information sharing (i.e., assurance) and/or seeking out information from a third party that confirms the partner's capabilities and motives (i.e., corroboration) (see Abbott 1993; Rose 1995).

Trust but verify?-Matching verification mode with level of trust

Drawing on these bodies of thought, a key contention advanced in this study is that while efforts toward verification can yield information helpful for addressing the quandary associated with trust, the ultimate implication of verification efforts for performance varies depending on the type of verification strategy employed and the level of trust present in an exchange. We examine the direct effects of each of the verification strategies in Table 1 and also suggest how each operates in combination with trust. A graphic overview of our research is presented in Fig. 1. Our contentions are consistent with more general insights developed in marketing (Heide et al. 2007; Noordewier et al. 1990; Wang et al. 2008) and related fields (Ittner et al. 1999; Poppo and Zenger 2002) that contend performance in an exchange is enhanced when congruence is present between the mechanisms of governance employed and the underlying circumstances of the exchange.

Performance and monitoring The observance of a partner's actions relating to exchange conduct and activities against implicit or explicit benchmarks provides one information strategy for addressing the dual implications for perfor-

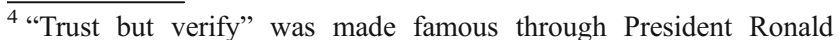
Reagan's approach and statement to then General Secretary Mikail Gorbachev during talks concerning strategic arms control in the late eighties. When asked whether he trusted the overtures being made by Gorbachev, Reagan replied "Doveryai, no proveryai," translated as "trust but verify" (New York Times, June 12, 1987, A12). Illustrating Reagan's appreciation for the complexities of trust, the phrase went on to become a lexicon of U.S. arms control policy during the Reagan era. The phrase has since served as a touchstone for scholars and others fascinated by the anomalies of trust and its relationship to other strategies of governance within interdependent exchanges (cf., Krass 1985).
} 
Table 1 Strategies of verification

\begin{tabular}{|c|c|c|c|c|}
\hline Concept description & $\begin{array}{l}\text { Governance } \\
\text { orientation }\end{array}$ & $\begin{array}{l}\text { Locus of } \\
\text { implementation }\end{array}$ & $\begin{array}{l}\text { Operationalization in buyer-supplier } \\
\text { exchange }\end{array}$ & $\begin{array}{l}\text { Representative } \\
\text { research }\end{array}$ \\
\hline \multicolumn{5}{|l|}{ Monitoring } \\
\hline $\begin{array}{l}\text { Procedures designed and incorporated } \\
\text { within an exchange relationship by one } \\
\text { party to acquire information and ascertain } \\
\text { a partner's activities and conduct. }\end{array}$ & Unilateral & Individual & $\begin{array}{l}\text { Formal supplier evaluation: Formal } \\
\text { collection of information on product } \\
\text { quality, delivery, price, support services, } \\
\text { etc., through inspection } \\
\text { and evaluation processes. }\end{array}$ & $\begin{array}{l}\text { Ittner et al. 1999; } \\
\text { Merchant 1990; } \\
\text { Heide et al. } \\
2007\end{array}$ \\
\hline \multicolumn{5}{|l|}{ Assurance } \\
\hline $\begin{array}{l}\text { Efforts by parties within an exchange } \\
\text { relationship to assemble and share } \\
\text { with their partner information concerning } \\
\text { their activities and conduct }\end{array}$ & Bilateral & Dyadic & $\begin{array}{l}\text { Information exchange: Sharing } \\
\text { of proprietary knowledge, joint planning } \\
\text { and sharing of cost, supply and demand } \\
\text { information }\end{array}$ & $\begin{array}{l}\text { Heide and John } \\
\text { 1992; Macneil } \\
1980\end{array}$ \\
\hline \multicolumn{5}{|l|}{ Corroboration } \\
\hline $\begin{array}{l}\text { Attempts by one party to seek } \\
\text { out information external to an exchange } \\
\text { relationship for evaluating and assessing } \\
\text { the activities and conduct of an exchange } \\
\text { partner }\end{array}$ & Trilateral & $\begin{array}{l}\text { Network (e.g., } \\
\text { Market) }\end{array}$ & $\begin{array}{l}\text { Actively monitoring the market: Checking } \\
\text { price and quality against competing } \\
\text { vendors, multiple sourcing, market } \\
\text { comparisons, soliciting competitive } \\
\text { bidding. }\end{array}$ & $\begin{array}{l}\text { Abbott 1993; } \\
\text { Anderson and } \\
\text { Oliver } 1987\end{array}$ \\
\hline
\end{tabular}

mance that attend trust in an exchange relationship (Ouchi 1979). Monitoring involves those procedures designed and incorporated within the relationship by one party to acquire information and ascertain a partner's actual performance (Anderson and Oliver 1987; Heide 1994; Wathne and Heide 2000).

In the buyer-supplier procurement context, formal supplier evaluation reflects a form of monitoring and involves the design and application of standardized, internal procedures for observing the supplier's performance directly and recording the results of these observations against explicit or implied benchmarks (Ouchi 1979). This can include procedures to ascertain the supplier's quality, formal evaluations of the supplier's service quality, or evaluation and recording of the delivery performance against predetermined standards.

As a general approach, monitoring may be characterized as a unilateral strategy for obtaining information concerning the actions of a partner. In contrast to alternatives, monitoring is implemented by one party versus jointly conducted (i.e., assurance) or externally acquired (i.e., corroboration). While less formal and extensive procedures may be employed, to its furthest degree, monitoring involves supervisory activities

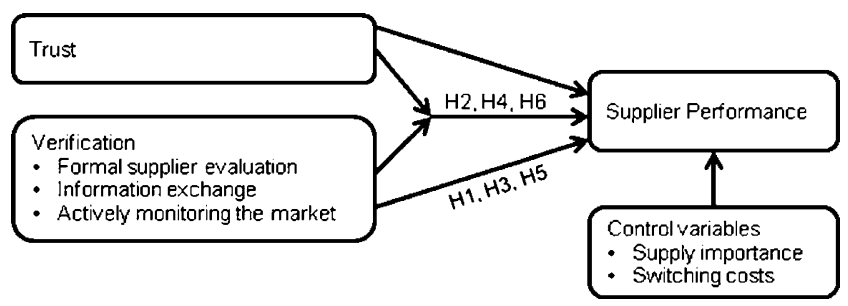

Figure 1 Trust and verification strategies in buyer-supplier relationships. designed to assess a partner's performance across all aspects of an exchange relationship (Noordewier et al. 1990).

Monitoring identifies specific aspects of a partner's performance which may be targeted for improvement. Monitoring can also provide performance incentives for the supplier through making it explicit that performance measurement is being conducted. Such activities help to enhance performance through simulating the control and enforcement benefits found within integrated hierarchies (Stinchcombe 1985). ${ }^{5}$ Following this reasoning, we predict:

$\mathrm{H}_{1}$ : In an exchange relationship, monitoring through procedures for formal evaluation has a positive effect on a partner's performance.

Performance implications of monitoring and trust Although obtaining information through formal supplier evaluation efforts can enhance performance in an exchange, the specific nature of this association may be dependent upon the extent of trust found in the relationship. In circumstances involving lower levels of trust by a party, more extensive evaluation is likely to provide added advantages for securing a partner's performance in an exchange.

\footnotetext{
${ }^{5}$ Indirect evidence of the performance enhancing benefits of at least one form of monitoring is provided by Noordewier et al. (1990). In their study of OEM purchasers, monitoring during the execution of an exchange agreement was conceptualized to be an element of relational governance. Their results suggest increasing the relational governance (including monitoring) of an exchange under conditions of high uncertainty leads to enhanced inventory and administrative performance.
} 
Absent a high level of trust that the partner will perform as expected, the additional control and enforcement benefits of procedures for more extensive monitoring can yield outcomes that help to enhance performance. These outcomes include providing for alternative or substitute sources of confidence in the exchange, compensating for the lack of trust and helping to create incentives for the partner to perform as expected (Jaworski 1988).

In the buyer-supplier context, adopting procedures for monitoring the actions and outputs of a supplier provides for an alternative source of confidence in the relationship, particularly when the supplier's credibility is low. Often a buyer must rely on a supplier's word or commitment about whether it can deliver by a certain date, produce to a certain quality level, or provide a high level of after sale support. The existence of formal evaluation procedures for monitoring these outcomes provides an added source of confidence on the part of the buyer, helping to enhance performance. Such procedures also provide an additional incentive for the supplier to live up to its promises as expected (Ouchi 1979).

In circumstances involving higher levels of trust, however, the performance implications of combining formal supplier evaluation with trust is less clear. As a strategy, monitoring involves unilateral actions which can be considered intrusive, in some cases resisted and in other cases result in dysfunctional outcomes (Merchant 1990). In circumstances involving higher trust, a trusted supplier may view the extensive reference to and use of such strategies as an attempt at control and may interpret such actions as taking away the supplier's independent decision authority (Murry and Heide 1998). The use of overt monitoring may be viewed by a supplier as incoherent (Wang et al. 2008) or inconsistent with the atmosphere in a high trust relationship and as such is harmful to exchange outcomes. The more heavy handed approach can discourage the voluntary willingness to cooperate and long-term perspective in a high trust relationship - such that the monitoring "crowds out" the benefits inherent from trust (Frey 1997). These lines of thought suggest that the positive effect of increased monitoring on performance may be attenuated at higher levels of trust - as the two modes may be redundant and operate as substitute mechanisms. We predict:

$\mathrm{H}_{2}$ : In an exchange relationship, the positive effect of monitoring on performance weakens at higher levels of trust.

Performance and assurances In contrast to monitoring a party to obtain information about its motives and capabilities, assurance involves exchange participants' efforts to affirmatively provide information in an effort to clarify their partner's expectations, reduce their uncertainty and/or elevate their confidence. Assurances can range from specific statements to more general disclosures of information. In this respect, efforts at assurance entail a party expending effort and resources to assemble information concerning its own activities and volitionally conveying this information to another (Abbott 1993). Closely allied with information exchange as conceived within the relational contracting framework (Macneil 1980), bilateral assurances involve the sharing of information with another (Cannon and Perreault 1999). As commonly practiced, assurance includes the provision of information that provides added knowledge regarding the partner's intentions, actions and performance. As a result, assurances through the open information exchange may be expected to facilitate positive outcomes for performance.

In the buyer-supplier context, information exchange includes affirmative statements as well as more general approaches that result in the open sharing of information about proprietary insights, relevant data on costs, product design decisions, or supply and demand forecasts. Parties may share such information in a bilateral sense through both providing information to one another about their activities and signaling their cooperative intentions.

Considerable work in marketing has examined and/or documented the performance enhancing benefits of information exchange (Heide and John 1992; Boyle et al. 1992; Gundlach and Achrol 1993; Noordewier et al. 1990; Gundlach et al. 1995). In related work, assurances through information sharing and exchange have been found to lead to improvements in product quality (Emshwiller 1991) and aid in the development of new products (Magnet 1994). Negotiations characterized by information sharing have also been observed to result in more optimal outcomes for both parties (Clopton 1984). Information exchange has also been reported to be associated with higher levels of relationship commitment-with buyers more likely to increase purchases from suppliers (Cannon and Homburg 2001). These findings and the prior explanations suggest the following main (and baseline) effect for the relationship of information exchange and performance:

$\mathrm{H}_{3}$ : In an exchange relationship, information exchange has a positive effect on a partner's performance.

Performance implications of assurance and trust While we predict information enhances performance, the specific nature of this relationship may also be dependent on the level of trust held by a party. In less trusting circumstances, a buyer is likely to require more credible and objective sources of information. Low trust in the relationship undermines the clarity, confidence building and uncertainty reducing processes expected to result from the sharing of information, thereby moderating its positive implications for performance. Simply put, the information obtained may 
not be "trusted," frustrating the positive effects of information exchange.

In contrast, information produced in more trusting relationships should be viewed as more credible and be acted upon. Under such circumstances, information obtained in this manner provides added clarity, builds confidence and reduces uncertainty about how a party will perform, thus bolstering trust's positive performance qualities while safeguarding against its attendant vulnerabilities. In high trust relationships, information exchange may suffice to provide these advantages. Trust complements information exchange - and both function better in the presence of the other. This suggests that the positive effects of information exchange on performance will strengthen at higher levels of trust in a relationship.

$\mathrm{H}_{4}$ : In an exchange relationship, the positive effect of information exchange on performance strengthens at higher levels of trust.

Corroboration and performance Where parties obtain information from sources external to their relationship in an effort to make comparative evaluations of relationship performance they rely on corroboration (Abbott 1993). While conceptualizations vary (Heide and John 1990), we define corroboration as a party's efforts to seek out information external to their relationship for evaluating and assessing the conduct and activity of an exchange partner. In this fashion, efforts to obtain corroborating information may be considered a trilateral strategy involving an informational source external to the dyadic relationship (e.g., the market or network) used internally by one party for comparative purposes.

In the buyer-supplier context, external information sources are frequently based on utilizing the market as a source of information. A common technique in buyersupplier relationships is to actively monitor the market for information regarding the quality of products and prices charged by a focal supplier, comparing these with alternative sources of supply (e.g., price catalogs, sales presentations) or through securing competitive bids (Bunn and Clopton 1993). Buyers often utilize multiple sources of supply to generate and validate outside information about production, costs, and quality of particular supplies; the information from one supplier can be used to calibrate information from an alternative source (Monczka et al. 2008). Reliance upon a sole source and failing to consider alternatives may be argued to comport to the absence of full external efforts at corroboration.

In terms of performance, beyond the specific benefits extending from obtaining added information through verification concerning an exchange partner relative to others, the process of verification itself can motivate performance by bringing to bear in a relationship the performance enhancing incentives of the "market." As a strategy, efforts at actively monitoring the market provide a method for obtaining information and serve as a basis for evaluating an exchange partner's performance against others in the market. To the extent these efforts reveal that better performance may be obtained elsewhere, they can serve to motivate a current partner to insure and enhance its own performance in the exchange. In this context, the prospect of losing business serves as a strong incentive for performance. Indeed, in some relationships a primary purpose for engaging in efforts to corroborate a partner's motives and capabilities is to provide continuous motivation for the partner to perform. Following this line of reasoning we predict the following main effect:

$\mathrm{H}_{5}$ : In an exchange relationship, actively monitoring the market has a positive effect on a partner's performance.

Performance implications of actively monitoring the market and trust While actively monitoring the market can help to motivate and incentivize performance, the specific nature of this relationship may further be dependent on the level of trust in the relationship. In trusting relationships, efforts at corroboration are likely to be more effective in those circumstances involving low trust. As mentioned, corroboration brings to bear in the relationship the performance enhancing incentives of the "market." With trust lacking, the implicit threat of business loss that accompanies the use of corroboration efforts is likely to motivate the partner to perform as expected.

However, in circumstances involving higher levels of trust, because of its trilateral nature, efforts to corroborate a partner's intentions and capabilities may have the potential of working at cross-purposes to trust. As with monitoring, validating a partner's performance and behavior by utilizing the implicit threats of other suppliers may conflict with those values inherent to trust and the enhanced relational qualities it engenders, resulting in the frustration of its positive performance implications. In essence, the process of corroboration itself may be perceived as incoherent and inconsistent with the high trust atmosphere in the relationship (Wang et al. 2008). More formal modes of governance can signal distrust and may encourage shirking (Ghoshal and Moran 1996; Macaulay 1963), which result in the crowding out of the benefits of relational exchange and trust (Frey 1997; Poppo and Zenger 2002). In higher trust relationships the implicit threat of the market mechanismthat an alternative source of supply may be used, or in the case of utilizing multiple suppliers, more business may be shifted to another supplier - may be viewed as a less credible threat, yielding less motivation to perform. 
Together, this reasoning suggests that the positive effect of increased verification on performance may diminish as trust reaches higher levels in a relationship.

$\mathrm{H}_{6}$ : In an exchange relationship, the positive effect of actively monitoring the market on performance weakens at higher levels of trust.

\section{Method}

As a basis for empirically examining the performance implications of information and trust in trusting relationships and testing the predicted relationships, a U.S. field study of buyer-supplier relationships was conducted. The sample and data collection method, measurement development and data analysis procedures employed in the study are described subsequently.

Sample and data collection

Sample frame Data were collected from a U.S. sample of buying organizations, each of which reported on its relationship with a particular supplier. The sample of respondents was drawn from across a variety of businessto-business exchange relationships (see below) in order to minimize the effect of industry specific practices and enhance the generalizability of the results.

Key informants Preliminary interviews ascertained that purchasing professionals met the criteria of being knowledgeable about the phenomenon under study (Campbell 1955). Typically, purchasing professionals have responsibility for understanding the supply market, managing supplier relationships, and monitoring and evaluating supplier performance, and work at the nexus of the buying center (Heide and John 1992).

Sample and unit of analysis The sample comprised 1007 members of the National Association of Purchasing Management. Its members are purchasing professionals engaged in procurement for organizations which have a primary business in manufacturing, distribution, services and government. The questionnaire directed these informants to select and report on a particular supplier relationship. Informants were asked to report on the "main supplier your firm chose for the last purchase" with which they were involved. This procedure avoided potential selection bias by respondents and assured respondent familiarity with the supplier.

A total of 28 of the mailings were returned due to wrong addresses or because the addressee no longer had contact with suppliers. In all, 231 completed surveys were received for a $24 \%$ response rate, a rate slightly below some studies of trust in business markets (Doney and Cannon 1997; Ganesan 1994) and higher than another (Morgan and Hunt 1994). One response was deleted because of excessive missing data, leaving a total of 230 relationships for analysis.

The above procedures produced a broad variety of different types of buyers and sellers. While most buying firms were engaged in manufacturing (59\%), the sample also included producers of services (including utilities and financial and educational institutions), distributors, and government agencies. Seller firms were primarily manufacturers $(56 \%)$ and distributors (36\%). Relationships averaged 11 years in length, although $15 \%$ were less than 2 years and $20 \%$ were more than 20 years long.

Informant qualification The quality of informant reports was evaluated by a series of questionnaire items which assessed each informant's confidence in their ability to respond to the questionnaire items, level of involvement with the supplier, and knowledge of their firm's dealings with the supplier (Kumar et al. 1992). While two respondents reported only modest involvement with the supplier (below the seven-point scale's midpoint), no responses were below the midpoint on the other two indicators. Thus, all 230 responses were deemed qualified and subsequently used for assessing nonresponse bias and for the measure analysis. The means on these three informant quality items were $6.5,6.5$, and 6.4.

Nonresponse bias Potential nonresponse bias was assessed using three separate tests. First, a pretest was used for measure development and to compare alternative forms of distribution of the questionnaires. In one condition, the researchers contacted 45 purchasing managers to solicit their participation - of this group 34 returned completed questionnaires $(76 \%)$. In a second condition, 362 purchasing managers were mailed a questionnaire without prenotification, and 123 (34\%) responded. Mean responses in each group were compared across relevant variables including characteristics of the respondents (e.g., percentage in managerial positions, involvement with supplier) and the business relationship (e.g., age of the relationship, number of seller representatives with contact). No differences were found, providing no evidence of differences between respondents and nonrespondents and supporting the view that nonresponse bias would not be a concern, and the final questionnaire was distributed by mail without prenotification.

As a second test, responses in the final sample were compared with those from the high response rate, phone prenotified, pretest group. Finally, early and late respond- 
ents in the final sample were compared on the same set of variables used in the previous tests (Armstrong and Overton 1977). For each of the comparisons across the three tests, no significant differences in means or proportions were found, suggesting nonresponse bias was not a concern.

Common method bias When a research study gathers data from a single respondent, there is the possibility of common method bias affecting the interpretation of the results. $A$ priori, this study utilized different types of scales across the measures and reverse worded items. Still, while common method bias is unlikely when interaction effects are tested and some hypotheses predict negative relationships (Slater and Atuahene-Gima 2004), we conducted two ex post tests to evaluate this possibility in these data. First, we compared a marker variable, unrelated to the variables in this study ("How involved are you in your firm's dealings with this supplier?"), and found it uncorrelated with all constructs in this study (Lindell and Whitney 2001; Malhotra et al. 2006). We also used a confirmatory factor analysis approach to Harmon's one-factor test (Podsakoff et al. 2003; Sanchez and Brock 1996). The rationale for this test is that if common method bias threatens results, then a single latent factor should explain the manifest variables as opposed to the hypothesized measurement model. A chisquare difference test found significantly improved fit for the five factor model $\left(\chi_{(10)}^{2}=2754.51 p<.01\right)$, suggesting no concern for common method bias. An exploratory factor analysis found many factors derived and explained $66.6 \%$ of the variance, while a single factor explained only $20.5 \%$ of the variance. Together these tests, and the correlation matrix including both positive and negative correlations, suggest that common method bias is not a concern with these data.

Control variables Central to our definition of trust was the need to distinguish its effects from dependence. Therefore, in addition to the theoretical constructs, we included measures of two aspects of dependence as control variables. In the organizational buying context of this study, two key aspects of buyer dependence are: (1) the importance of supply for a product and (2) the costs to switch to an alternative supplier. By controlling for the effects of dependence in the relationship, the empirical study provides a stronger test of the proposed relationships.

\section{Measurement development procedures}

The focal constructs for this research represent business practices that reflect the theoretical constructs identified in the literature. Each measure was developed following standard psychometric scale construction and evaluation procedures (Anderson and Gerbing 1988; Churchill 1979). Multi-item scales were generated based on a review of the literature and interviews with marketing and purchasing personnel and were refined through a series of pretests. Some of the scales have been previously published.

Item scale construction A number of steps were taken in constructing the measurement scales employed in the study. The first version of the questionnaire was administered to six purchasing managers, who were interviewed immediately afterward by a researcher. Next, sixteen participants in an executive education seminar completed the survey. Finally, 407 members of a regional purchasing association were mailed the survey and the 157 responses were analyzed. At each stage items and instructions were modified and refined. The final questionnaire still included a large number of items for each construct, and the psychometric properties of the final measures were assessed and further purified with confirmatory factor analysis procedures using LISREL VIII (Jöreskog and Sörbom 1993) as well as traditional methods (e.g., coefficient alpha and adjusted item-to-total correlations). The actual measures used for the study are reported in the Appendix.

Item scale analysis Table 2 reports summary statistics and a correlation matrix for the scales. These statistics show that the scales exhibit sufficient variance and reliability. Reliability of the measures ranges from .77-.89 for coefficient alpha and $.80-.91$ on composite reliability. Though the average variance extracted for the measure of information exchange is slightly below the minimum recommended by Bagozzi and Yi (1988), others meet this criterion.

Convergent and discriminant validity were evaluated using confirmatory factor analysis procedures, except for the measure of monitoring, which was constructed as a formative scale. Because of the large number of items relative to the sample size, confirmatory factor analyses were performed separately for the theoretical constructs and the control variables. The key fit statistics for the two models are shown at the bottom of Table 2, and they suggest these data fit the measurement model. In addition, each indicator is statistically significant with parameter estimates ranging from 9-16 times as large as the standard errors. Together, these findings provide evidence of convergent validity for the measures.

Evidence of discriminant validity was assessed through three methods. First, we examined the estimated correlations in the phi matrix to determine if the $95 \%$ confidence intervals contain correlations less than one. In addition, we performed a comparison of the nested confirmatory factor models with correlation parameters constrained to 1.0 (Anderson and Gerbing 1988). Finally, we conducted the more stringent test suggested by Fornell and Larcker 
Table 2 Mean, standard deviation, range, reliability, and correlation matrix for measures

\begin{tabular}{|c|c|c|c|c|c|c|c|c|c|c|c|}
\hline Scale name & Mean & std & Range & Reliability $^{\mathrm{a}}$ & AVE & 1 & 2 & 3 & 4 & 5 & 6 \\
\hline 1. Trust of supplier & 5.61 & 1.16 & $1-7$ & $.81 / .84$ & .58 & & & & & & \\
\hline 2. Monitoring with Formal Supplier Evaluation & 4.94 & 1.28 & $1-7$ & $\mathrm{n} / \mathrm{a}$ & $\mathrm{n} / \mathrm{a}^{\mathrm{b}}$ & .16 & & & & & \\
\hline 3. Information Exchange & 4.11 & 1.54 & $1-7$ & $.77 / .80$ & .49 & .30 & .28 & & & & \\
\hline 4. Actively Monitoring the Market & 4.58 & 1.49 & $1-7$ & $.77 / .82$ & .53 & .10 & .19 & -.08 & & & \\
\hline 5. Supplier Performance & 5.69 & 0.91 & $1-7$ & $.85 / .86$ & .62 & .65 & .24 & .33 & .11 & & \\
\hline 6. Importance of Supply & 5.83 & 1.10 & $1.75-7$ & $.83 / .89$ & .68 & .06 & .27 & .13 & -.03 & .03 & \\
\hline 7. Switching Costs & 4.77 & 1.51 & $1-7$ & $.89 / .91$ & .72 & -.10 & .21 & .16 & -.32 & .02 & .27 \\
\hline
\end{tabular}

Correlations $>.11(p<.05) ;>.16(p<.01)$

${ }^{\text {a }}$ Reliability statistics reported are coefficient alpha / composite reliability

b Reliability and average variance extracted are not appropriate tests for formative measures

Confirmatory factor analysis fit statistics for theoretical/control variable models: chi-square=207.08 w/ 96 d.f. $(p<.01) / 38.21 \mathrm{w} / 19$ d.f. $(p<.01)$; RMSEA $=.065 / .067$; GFI $=.91 / .96$; CFI $=.97 / .98 ; \mathrm{IFI}=.97 / .98$

(1981), which demonstrates discriminant validity by showing that the average variance extracted exceeds the squared correlation between all pairs of constructs. The results of each test provided strong evidence of discriminant validity between all pairs of constructs.

As a formative scale, formal supplier evaluation was developed in collaboration with purchasing professionals who understood the domain of different dimensions of performance typically assessed. Indicator collinearity was also evaluated. The highest variance inflation factor of 3.51 was well below the typical cut-off threshold of 10 (Diamantopoulos and Winklhofer 2001). The procedure and assessment provide evidence of the scale's validity.

\section{Data analysis procedures}

The proposed hypotheses were tested using hierarchical moderator regression. Because many of the hypotheses required demonstrating the presence of an interaction, the analysis involved a multi-stage process. First, the set of interaction terms were evaluated to determine whether they added significantly to the explained variance of the model (Cohen and Cohen 1983). This involved (1) an omnibus hierarchical regression moderator test to determine whether adding all three interaction terms explained significantly more variance and (2) a series of nested tests that compare the maineffects only model with the addition of each interaction term.

A final step in the analysis involved assessment of the nature of the specific interactions. Procedures suggested by Aiken and West (1991) for testing conditional effects were followed. The presence of a significant interaction indicates that the effect of an independent variable (i.e., a verification strategy) is conditional upon the level of another independent variable (i.e., trust). Through centering the data at its mean, the "main effects" indicate the effect of the independent variable at the mean level of the interacting variable. By re-centering the data around a higher value (i.e., one standard deviation higher than the mean), the effects of an independent variable (i.e., an information strategy) at a high level of another independent variable (i.e., trust) is determined. This approach results in a more detailed picture of the interaction effects.

\section{Results}

The results of the regression analysis are reported in Table 3. The first column provides a baseline main-effects only model. Tests for collinearity showed variance inflation factors for each independent variable below 2.0, and well below 10.0 - the level at which one should be concerned (Belsley et al. 1980). The initial model is statistically significant and explains an adjusted $45 \%$ of the variance in supplier performance.

The omnibus hierarchical moderator regression test (Cohen and Cohen 1983) indicates that the inclusion of the interaction terms significantly improves explained variance in supplier performance $\left(\mathrm{F}_{(3,217)}=2.71 ; p<.05\right)$. These results indicate that the models in Table 3 can be used to test the hypotheses involving the interaction terms.

Performance implications of verification strategies in trusting relationships

Formal supplier evaluation $\mathrm{H}_{1}$ examines the effects of monitoring through formal supplier evaluation on supplier performance, predicting a positive main effect on performance. Formal supplier evaluation simulates the control and enforcement benefits found within integrated hierar- 
Table 3 Results of moderated multiple regression, hypothesis tests, and effects at moderate, high and low levels of trust

\begin{tabular}{|c|c|c|c|c|c|c|c|}
\hline Independent variables & $\begin{array}{l}\text { Baseline } \\
\text { model }\end{array}$ & $\begin{array}{l}\text { Nested: trust* } \\
\text { Mon. }\end{array}$ & $\begin{array}{l}\text { Nested: } \\
\text { trust* IX }\end{array}$ & $\begin{array}{l}\text { Nested: } \\
\text { trust*AMM }\end{array}$ & $\begin{array}{l}\text { Trimmed } \\
\text { model }\end{array}$ & $\begin{array}{l}\text { High trust } \\
(+1 \text { s.d. })\end{array}$ & $\begin{array}{l}\text { Low trust } \\
(-1 \text { s.d. })\end{array}$ \\
\hline \multicolumn{8}{|c|}{ Theoretical Constructs-Main Effects } \\
\hline Trust of Supplier & $.59^{\mathrm{a}}$ & $.59^{\mathrm{a}}$ & $.59^{\mathrm{a}}$ & $.59^{\mathrm{a}}$ & $.60^{\mathrm{a}}$ & $.60^{\mathrm{a}}$ & $.60^{\mathrm{a}}$ \\
\hline $\begin{array}{l}\text { Monitoring with Formal } \\
\text { Supplier Evaluation }\end{array}$ & $.07\left(\mathrm{H}_{1}\right)$ & .07 & .07 & .07 & $.08^{\mathrm{c}}$ & $.08^{\mathrm{c}}$ & $.08^{\mathrm{c}}$ \\
\hline Information Exchange & $.15^{\mathrm{a}}\left(\mathrm{H}_{3}\right)$ & $.16^{\mathrm{a}}$ & $.14^{\mathrm{a}}$ & $.14^{\mathrm{a}}$ & $.10^{\mathrm{b}}$ & $.23^{\mathrm{a}}$ & -.03 \\
\hline Actively Monitoring the Market & $.10^{\mathrm{b}}\left(\mathrm{H}_{5}\right)$ & $.11^{\mathrm{b}}$ & $.12^{\mathrm{b}}$ & .09 & $.10^{\mathrm{b}}$ & -.03 & $.22^{\mathrm{a}}$ \\
\hline \multicolumn{8}{|c|}{$\begin{array}{l}\text { Theoretical Constructs-Interaction } \\
\text { Effects }\end{array}$} \\
\hline $\begin{array}{l}\text { Trust*Monitoring with Formal } \\
\text { Sup. Evaluation }\end{array}$ & & $.03\left(\mathrm{H}_{2}\right)$ & & & & & \\
\hline Trust* Information Exchange & & & $.10^{\mathrm{b}}\left(\mathrm{H}_{4}\right)$ & & $.09^{\mathrm{b}}$ & $.15^{\mathrm{b}}$ & $.08^{\mathrm{c}}$ \\
\hline $\begin{array}{l}\text { Trust*Actively Monitoring the } \\
\text { Market }\end{array}$ & & & & $-.11^{\mathrm{b}}\left(\mathrm{H}_{6}\right)$ & $-.10^{\mathrm{b}}$ & $-.18^{\mathrm{b}}$ & $-.11^{\mathrm{b}}$ \\
\hline \multicolumn{8}{|l|}{ Control Variables } \\
\hline Importance of Supply & -.06 & -.06 & -.06 & -.06 & -.06 & -.06 & -.06 \\
\hline Switching costs & .08 & .08 & .08 & .08 & .09 & .09 & .09 \\
\hline $\mathrm{F}$ & $32.65^{\mathrm{a}}$ & $27.97^{\mathrm{a}}$ & $28.81^{\mathrm{a}}$ & $29.02^{\mathrm{a}}$ & $26.09^{\mathrm{a}}$ & $26.09^{\mathrm{a}}$ & $26.09^{\mathrm{a}}$ \\
\hline Adjusted $\mathrm{R}^{2}$ & .45 & .45 & .46 & .46 & .47 & & \\
\hline$\Delta$ Adjusted $\mathrm{R}^{2}$ & & $.00\left(\mathrm{H}_{2}\right)^{*}$ & $.01^{\mathrm{b}}\left(\mathrm{H}_{4}\right)^{*}$ & $.01^{\mathrm{b}}\left(\mathrm{H}_{6}\right)^{*}$ & $.02^{\mathrm{b}}$ & & \\
\hline
\end{tabular}

${ }^{\mathrm{a}} p<.01 ;{ }^{\mathrm{b}} p<.05 ;{ }^{\mathrm{c}} p<.10$ (t-tests are one-tail)

Table reports standardized parameter estimates

* F-test for the significance of the increase in proportion of variance explained after adding each interaction.

chies. Although a positive relationship was found, the effect was not significant $(\beta=.07 ; \mathrm{p}=\mathrm{n} . \mathrm{s}$. $)$. Thus, the predicted positive main effect of monitoring on performance is not supported.

$\mathrm{H}_{2}$ predicts that the unilateral nature of monitoring conflicts with the collaborative spirit inherent in trusting relationships. The second column in Table 3 reports the results of adding the trust $\mathrm{x}$ formal supplier evaluation interaction term. The coefficient for the interaction term is not statistically significant $(\beta=.03)$, and after adjusting for degrees of freedom, there is no incremental variance explained by adding this term to the model. The results do not provide support for $\mathrm{H}_{2}$.

Information Exchange $\mathrm{H}_{3}$ examines the effects of information exchange on supplier performance. Information exchange enables both partners to better understand the other's performance capabilities and needs. Our findings support the prediction of $\mathrm{H}_{3}$ for the main effect of assurance in the trimmed model $(\beta=.15 ; p<.01)$.

$\mathrm{H}_{4}$ predicts that the positive effect of information exchange on performance strengthens at higher levels of trust. Thus, $\mathrm{H}_{4}$ predicted an interaction between trust and information exchange on performance. This prediction is also supported. The incremental variance explained $(\Delta$ adjusted $\mathrm{R}^{2}=.01$ ), while modest, is statistically significant $(p<.05)$ as is the coefficient for the interaction of trust and assurance $(\beta=.10 ; p<.05)$.

Because $\mathrm{H}_{4}$ indicates that the positive effect of information exchange is stronger at higher levels of trust, we follow the procedures suggested by Aiken and West (1991) for testing and exploring the nature of the conditional effects. This was accomplished through re-centering the values for trust at a level one standard deviation above (and below) the mean. After making these adjustments, the coefficient for the "main effect" of information exchange in each model reflects the effect of information exchange at each level of trust. The last two columns in Table 3 present the results for higher and lower levels of trust. The results provide further support (and explanation) for the hypothesis, showing that at higher levels of trust, the effects of information exchange on performance is positive and significant $(\beta=.23 ; p<.01)$. When trust is low, the effect of information exchange on performance is not significant $(\beta=-.03 ; p=$ n.s. $)$. Figure 2 graphically shows these effects.

Actively monitoring the market $\mathrm{H}_{5}$ examines the effect of corroboration efforts through actively monitoring the market on supplier performance. Actively monitoring the market provides incentives for suppliers to perform at a high level. Buyers generate information by utilizing multiple sources of supply or seeking bids from other sources. The results support 


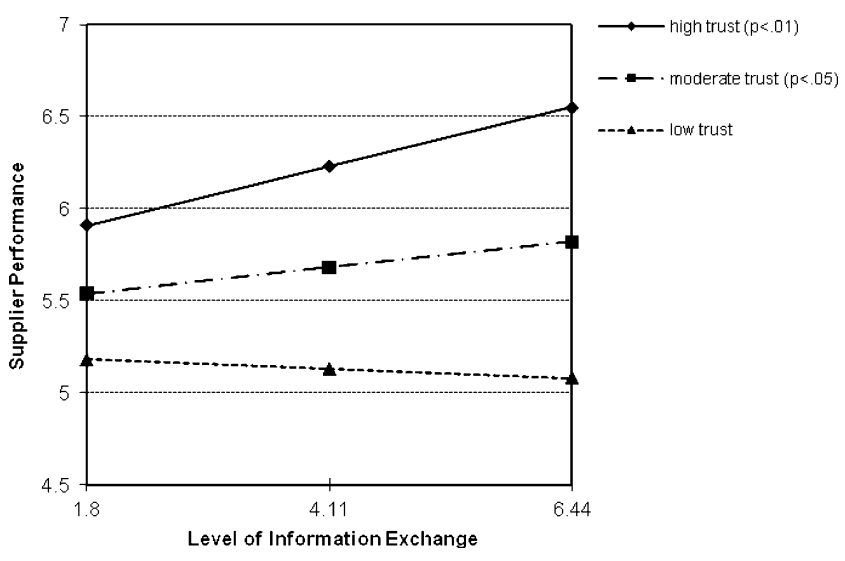

Figure 2 Conditional effects of information exchange on supplier performance at three levels of trust.

the predicted main effect. The incremental variance explained ( $\Delta$-adjusted $\mathrm{R}^{2}=.01$ ) and coefficient for the interaction term $(\beta=.10 ; p<.05)$ are both statistically significant.

$\mathrm{H}_{6}$ predicts that the positive effects of actively monitoring the market weaken at higher levels of trust. The interaction between trust and actively monitoring the market is statistically significant $(\beta=-.11 ; p<.05)$, providing support for $\mathrm{H}_{6}$. Moreover, following the previously described procedures at higher and lower levels of trust, the results provide further support for $\mathrm{H}_{6}$ and explain the predicted effect: verification has no significant effect on performance when trust is high $(\beta=-.03 ; \mathrm{p}=$ n.s. $)$ but has a strong impact when trust is low $(\beta=.22 ; p<.01)$. These findings are presented graphically in Fig. 3.

\section{Discussion and implications}

The importance of trust and its benefits in modern exchange are not settled. Trust remains a complex and elusive

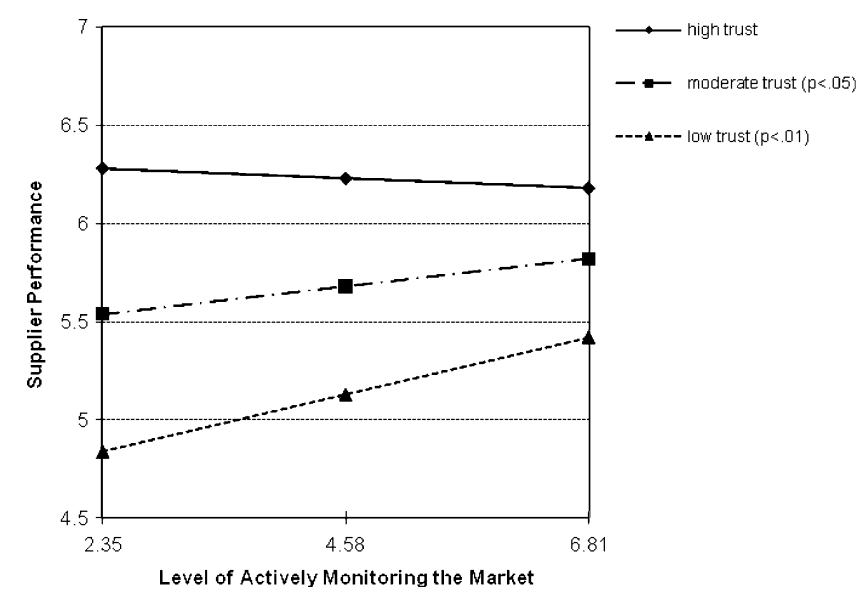

Figure 3 Conditional effects of actively monitoring the market on supplier performance at three levels of trust. construct — worthy of more thorough analysis and a deeper understanding. Prompted by reassessment of cooperative exchange relationships involving trust, the unique nature of trust has led to increasing interest and inquiry as to its various properties and their implications for the management and performance of such exchanges. In the current study, we described the dilemma of trust or the understanding that while providing benefits to exchange, trust also involves the accepted potential of loss from adverse outcomes that may occur in the event a trusted partner takes advantage of another's trust. Accepting this property as an inherent aspect of trust within exchange relationships, we empirically examined how a party, attempting to insure expected performance in an exchange, may combine its trust with verification efforts geared at obtaining information about a partner. Three different verification strategies common to exchange relationships and their implications for performance at differing levels of trust were examined. Drawing on research that examines how multiple governance modes may combine in a complementary manner to enhance performance or may be redundant and detrimental to optimum performance, we proposed and tested a series of hypotheses employing a U.S. sample of purchasing professionals.

Our findings reveal that depending on the level of trust in a relationship, the three strategies used to gather information combine with trust in different ways to affect performance. Two of the verification strategies yielded a direct, positive effect on supplier performance-assurance through information exchange and corroboration through actively monitoring the market. Yet as predicted, these benefits were found to be contingent on the level of trust and the specific information production strategy employed. When buyers had a high level of trust in a supplier, the use of information exchange further enhanced performance. On the other hand, when trust was low, information exchange provided no additional performance benefits. The interaction of trust and actively monitoring the market was in the opposite direction. When a supplier was highly trusted, increased market monitoring had no effect on performance. On the other hand, when trust of a supplier was low, increased market monitoring enhanced the supplier's performance. Predictions regarding the role of formal supplier evaluation were not supported.

\section{Exchange management}

Ranging from consumer to business exchange, virtually all modern marketing relationships involve trust. Although trust provides an important basis for these exchanges, trust in another party also implies acceptance of the potential that the trusted partner may not perform as expected. As a result, those involved in trusting relationships may combine 
their trust with verification strategies to safeguard against such outcomes and ensure optimal exchange performance. Strategies intended to augment trust by producing information provide one option for such an approach. For the ongoing management of relationships involving trust and relying on verification, the findings of this study provide important implications.

Specifically, the findings of this study suggest that a buyer's selection of a particular verification strategy can have implications for the supplier's performance. Depending on the level of trust and the information approach employed, differing performance implications attend their combination. The findings indicate that for moderate and higher trust relationships, assurance strategies are likely to yield the greatest performance benefits. For lower trust relationships, verification is likely to be the better choice. In higher trust exchanges, the added confidence and confirmation of expectations provided through strategies of assurance appear to bolster trust's positive performance qualities while safeguarding against its attendant vulnerabilities. In lower trust exchanges, through use of verification strategies, the incentive benefits of the market appear to facilitate enhanced performance.

Use of information exchange in trusting relationships Information exchange strategies are bilateral activities requiring the cooperation of an exchange partner. As our results suggest, information exchange and trust offer complementary governance benefits, thereby enhancing performance. Such performance implications, however, are particular to only moderate and high trust relationships. Under lower trust circumstances, information exchange does not provide significant enhancements to performance when combined with trust. In all likelihood, under low trust circumstances, information generated through information exchange has less credibility and therefore may have little impact on behavior. Those involved in trusting relationships should recognize the benefits of assurance strategies for high trust relationships, but also realize their shortcomings for low trust exchanges (Williamson 1985).

Use of actively monitoring the market in trusting relationships Actively monitoring the market through the use of multiple suppliers or by regularly seeking bids or input from other alternatives is a common purchasing practice. As a verification strategy it relies on a network or marketbased approach and does not require the acquiescence or cooperation of an exchange partner. Our results suggest the performance benefits of verification primarily attend low trust exchanges. In these exchanges, verification efforts supplement trust through the incentives and workings of the market. For higher trust relationships, verification did not provide positive enhancements to performance. For these exchanges, verification efforts may work at cross purposes to trust, frustrating its performance enhancing benefits. Those involved in trusting relationships should realize these contrasting properties when combining verification strategies with trust in their exchanges.

Use of formal supplier evaluation in trusting relationships Finally, monitoring strategies generally involve a unilateral activity, but they require the acquiescence and involvement of the other party. Their use can be effective through simulating the control and enforcement of a hierarchy, but in the wrong circumstances they may be viewed as intrusive and too extensive. In the current study, though positively (but not significantly) related to performance, the extensiveness of formal procedures for monitoring and evaluating a supplier did not provide significant enhancements to performance when combined with trust.

We predicted the effects of trust and monitoring in combination would be detrimental to performance (Heide et al. 2007). Finding valid arguments that the two forms of governance operated as substitutes and may be incompatible, we proposed that the effects of monitoring would diminish when trust was higher. These predictions were not supported. An alternative argument could be made that trust and monitoring complement one another and that a more trusted supplier may take the input from formal supplier evaluation in a more constructive manner, positively influencing behavior and supplier performance (Liker and Choi 2004). Perhaps both effects were operating - within the same relationships or across relationships - cancelling out an effect.

Finally, it is important to note that beyond information gathering, in an effort to maximize the performance benefits of trust and safeguard against the vulnerability of trust, managers may also call upon other strategies of governance. Arrangements for the production of information are just one alternative. Managers may also wish to consider and evaluate other strategies for their performance implications relative to trust. At a basic level, these strategies should either provide incentives and safeguards against the violation of trust or serve to bolster and complement the positive benefits of trust. Strategies that accomplish both outcomes should be considered optimal.

Theory and directions for future research

The findings in the current study shed light on the nature of trust and how trust operates in exchange relationships. The dilemma of trust provides important insights in this respect. While trust may be present, its presence does not typically 
result in the elimination of other modes of governance. The acquisition of information may be used to partially offset the risks inherent in granting trust or to complement the trust that exists in the relationship.

The findings also contribute to the growing literature on complex management forms of organization attendant to cooperative exchange, e.g., plural forms governance. Increasing attention in marketing focuses on exactly how different mechanisms of governance work in combination (Cannon et al. 2000; Poppo and Zenger 2002), acknowledging the plural forms thesis. There is a great need to understand which mechanisms complement one another and fill governance gaps - and which mechanisms are redundant and inefficient. In this regard, the current work helps to further our understanding of how and why trust may operate in combination with other forms of governance and, in particular, information production which has a cost.

Researchers investigating trust in ongoing exchange should also benefit from the conceptual focus, theoretical development and empirical tests conducted in the current study. To date, while acknowledging the accepted potential of loss associated with trust, few researchers have focused attention on the implications of this unique property from a governance perspective. Continued research is suggested to fully understand its implications, with further empirical tests required to fully support the relationships proposed and tested here. Several paths are encouraged including elaboration and investigation of other methods through which information may be obtained and the use of other governance strategies.

The current study focused attention on the use of different information production approaches that may enhance performance. Prior conceptual development has not emphasized the distinct nature of these strategies. The framework of information production arrangements developed for the study distinguishes their strategic orientation and locus of implementation. Future research may wish to develop this framework further through adding other information production approaches and highlighting their differences, or through identifying information sources prominent in other exchange contexts. The temporal nature of trust and information sources could also be explored to understand their use at different stages in the relationship (Anderson and Jap 2005).

The results obtained for the study suggest the use of differing information approaches results in unique outcomes for performance when employed in relationships possessing varying levels of trust. Future research may also wish to investigate other strategies beyond information that may be combined with trust for their performance implications. Drawing on various disciplines (e.g., economics, law, and sociology), an emerging tradition in marketing emphasizes the multitude of approaches available for managing exchange and how such approaches may be combined to enhance performance. Research examining the nature of the interrelationship between trust and these other managerial mechanisms will help to gain a better understanding of exchange overall.

\section{Limitations}

As with any study, the results of the current study must be interpreted in the context of the limitations and constraints which attend its concepts, design, measurement and analysis. Though emphasizing theory development and testing, the explained variance and coefficients obtained for the predicted interaction effects of trust and information production strategies are not substantively large. Yet in hypercompetitive markets, managers frequently seek sources of even modest performance improvements. Inferences extending from these interpretations should therefore be considered more appropriate to the theoretical domain. In addition, while the study includes various control variables in an effort to strengthen the subsequent test of the hypothesized relationships, other control variables may have importance in explaining these associations. Moreover, though providing advantages to generalizability, the use of an across industry sample of buyers and suppliers can introduce uncontrolled error. In each case, additional studies incorporating other controls and different samples are needed to verify the obtained results.

In addition, notwithstanding efforts in measure development and assessment, our measures could be improved upon. As intimated, issues remain in the development of measures which capture the concept of trust. In the current study, reliance was given to items which captured in a straightforward manner both trusting intentions and behavior. More depth measurement of these aspects of trust may provide stronger and more valid measures. In addition, our measures of the various information production approaches focus on particular aspects of each of these concepts. Other aspects or broader operationalizations may provide distinct results from those obtained. Our global measure of performance may not fully capture the extensive aspects of this construct-or the effects of trust and information strategies on other dimensions of performance (e.g., efficiency aspects such as transaction costs and other aspects of effectiveness). The measurement of some constructs may also have benefitted with input from multiple respondents or supplier side measures (Blois 1999). Future research might address these and other limitations of this study and identify other insights about the nature of trust in exchange. 


\section{Appendix}

Table 4 Measures

Scale Name (response cues) (source of scale)

Trust of Supplier (strongly disagree - strongly agree) (Doney and Cannon 1997)

This is one of the most trustworthy suppliers with whom we do business.

Sometimes this vendor is not completely honest with us. (R)

We trust that this supplier keeps our best interests in mind.

We sometimes find it necessary to be cautious with this supplier. (R)

Monitoring: Formal Supplier Evaluation (no formal procedures-extensive procedures)

product quality

delivery performance

price

sales, service, and/or technical support

total value received

overall supplier performance

Assurances: Information Exchange (very inaccurate description - very accurate description) (Cannon and Perreault 1999)

Proprietary information is shared with each other.

We will both share relevant cost information.

We include each other in product development meetings.

We always share supply and demand forecasts.

Corroboration: Actively Monitoring the Market (strongly disagree — strongly agree) (Cannon and Homburg 2001)

We usually get more than one bid when we purchase this product.

This supplier is our sole source for this product. (R)

We often check the price and quality of other vendors of this product.

We do not even consider other suppliers for purchases of this product. (R)

Performance of supplier (needs improvement—superior performance) (Cannon and Perreault 1999)

product quality

delivery performance

sales, service and/or technical support

total value received

Supply Importance (“Compared to other purchases your firm makes, this product is:”) (Cannon and Homburg 2001)

important—unimportant (R)

nonessential—essential

high priority-low priority $(\mathrm{R})$

insignificant—significant

Switching Costs (“... which term most closely reflects the difficulty in replacing this supplier”)

easy—hard

costly-expensive (R)

quick - time consuming

complicated—simple (R)

(R) Reverse-coded items 


\section{References}

Abbott, K. W. (1993). Trust but verify: the production of information in arms control treaties and other international agreements. Cornell International Law Journal, 26, 1-58.

Agustin, C., \& Singh, J. (2005). Curvilinear effects of customer loyalty determinants in relational exchange. Journal of Marketing Research, 96-108.

Ahearne, M., Jelinek, R., \& Jones, E. (2007). Examining the effect of salesperson service behavior in a competitive context. Journal of the Academy of Marketing Science, 603-616.

Aiken, K. D., \& Boush, D. M. (2006). Trustmarks, objective-source ratings, and implied investments in advertising: investigating online trust and the context-specific nature of internet signals. Journal of the Academy of Marketing Science, 308-323.

Aiken, L. S., \& West, S. G. (1991). Multiple regression: Testing and interpreting interactions. Newbury Park: Sage.

Anderson, J. C., \& Gerbing, D. W. (1988). Structural equation modeling in practice: a review and recommended two-step approach. Psychological Bulletin, 103(3), 411-423.

Anderson, E., \& Jap, S. D. (2005). The dark side of close relationships. MIT Sloan Management Review, 46, 75-82.

Anderson, E., \& Oliver, R. L. (1987). Perspectives on behavior-based versus outcome-based salesforce control systems. Journal of Marketing, 76-88.

Anderson, E., \& Weitz, B. A. (1989). Determinants of continuity in conventional industrial channel dyads. Marketing Science, 8 , 310-323.

Armstrong, J. S., \& Overton, T. S. (1977). Estimating nonresponse bias in mail surveys. Journal of Marketing Research, 14, 396-402.

Atuahene-Gima, K., \& Li, H. (2002). When does trust matter? Antecedents and contingent effects of supervisee trust on performance in selling new products in China and the United States. Journal of Marketing, 66, 61-81.

Aulakh, P. S., Kotabe, M., \& Sahay, A. (1996). Trust and performance in cross-border marketing partnerships: a behavioral approach. Journal of International Business Studies, 27(5), 1005-1032.

Bagozzi, R. P., \& Yi, Y. (1988). On the evaluation of structural equation models. Journal of the Academy of Marketing Science, 16(1), 74-97.

Belsley, D. A., Kuh, E., \& Welsh, R. E. (1980). Regression diagnostics: Identifying influential data and sources of collinearity. New York: Wiley and Sons.

Bergen, M., Dutta, S., \& Walker, O. C., Jr. (1992). Agency relationships in marketing: a review of the implications and applications of agency theory and related theories. Journal of Marketing, 56, $1-24$.

Blois, K. J. (1999). Trust in business to business relationships: an evaluation of its status. Journal of Management Studies, 36, 197215.

Boyle, B., Dwyer, R. F., Robicheaux, R. A., \& Simpson, J. T. (1992). Journal of Marketing, 29(4), 462-474.

Bradach, J. L., \& Eccles, R. G. (1989). Price, authority, and trust. Annual Review of Sociology, 15, 97-118.

Bunn, M. D., \& Clopton, S. W. (1993). Patterns of information source use across industrial purchase situations. Decision Sciences, 24 (2), 457-478.

Campbell, D. T. (1955). The informant in quantitative research. American Journal of Sociology, 60, 339-342.

Cannon, J. P., \& Homburg, C. (2001). Buyer-supplier relationships and customer firm costs. Journal of Marketing, 65, 29-43.

Cannon, J. P., \& Perreault, W. D., Jr. (1999). Buyer-seller relationships in business markets. Journal of Marketing Research, 36, 439-461.
Cannon, J. P., Achrol, R., \& Gundlach, G. T. (2000). Contracts norms, and plural form governance. Journal of the Academy of Marketing Science, 28, 180-194.

Celly, K. S., \& Frazier, G. L. (1996). Outcome-based and behaviorbased coordination efforts in channel relationships. Journal of Marketing Research, 33(2), 200-211.

Chiou, J.-S., \& Droge, C. (2006). Service quality, trust, specific asset investment, and expertise: direct and indirect effects in a satisfaction-loyalty framework. Journal of the Academy of Marketing Science, 34(4), 613-627.

Churchill, G. A., Jr. (1979). A paradigm for developing better measures of marketing constructs. Journal of Marketing Research, 16, 64-73.

Clopton, S. W. (1984). Seller and buying firm factors affecting industrial buyers' negotiation behavior and outcomes. Journal of Marketing Research, 21, 39-53.

Cohen, J., \& Cohen, P. (1983). Applied multiple regression/correlation analysis for the behavioral sciences (2nd ed.). Hillsdale: Lawrence Erlbaum Associates.

Crosby, L. A., Evans, K. A., \& Cowles, D. (1990). Relationship quality in services selling: an interpersonal influence perspective. Journal of Marketing, 54(3), 68-82.

Dahlstrom, R., \& Nygaard, A. (1995). An exploratory investigation of interpersonal trust in new and mature market economies. Journal of Retailing, 339-362.

Deutsch, M. (1958). Trust and suspicion. Journal of Conflict Resolution, 2, 265-79.

Deutsch, M. (1962). Cooperation and trust: Some theoretical notes. In M. R. Jones (Ed.), Nebraska symposium on motivation (pp. 275320). Lincoln: University of Nebraska Press.

Diamantopoulos, A., \& Winklhofer, H. M. (2001). Index construction with formative indicators, An alternative to scale development. Journal of Marketing Research, 38, 269-277.

Dirks, K. T. (1999). The effects of interpersonal trust on work group performance. Journal of Applied Psychology, 84(3), 445-455.

Doney, P. M., \& Cannon, J. P. (1997). An examination of the nature of trust in buyer-seller relationships. Journal of Marketing, 61, 3551.

Dore, R. (1983). Goodwill and the spirit of market capitalism. British Journal of Sociology, 34, 459-482.

Emshwiller, J. R. (1991). Suppliers struggle to improve quality as big firms slash their vendor rolls. Wall Street Journal, B1, B2.

Fornell, C., \& Larcker, D. F. (1981). Evaluating structural equation models with unobservable variables and measurement errors. Journal of Marketing Research, 18, 39-51.

Frazier, G. L., \& Sheth, J. N. (1985). An attitude-behavior framework for distribution channel management. Journal of Marketing, 49 (3), 38-49.

Frazier, G. L., \& Summers, J. O. (1984). Interfirm influence strategies and their application within distribution channels. Journal of Marketing, 48, 43-55.

Frey, B. (1997). A constitution for knaves crowds out civic virtues. Economic Journal, 107, 1043-1053.

Gambetta, D. (1988). Can we trust trust. In D. Gambetta (Ed.), Trust (pp. 213-237). Oxford: Basil Blackwell.

Ganesan, S. (1994). Determinants of long-term orientation in buyerseller relationships. Journal of Marketing, 58, 1-19.

Geyskens, I., Steenkamp, J.-B. E. M., \& Kumar, N. (1998). Generalizationas about trust in marketing channel relationships using meta-analysis. International Journal of Research in Marketing, 15(3), 223-248.

Ghoshal, S., \& Moran, P. (1996). Bad for practice: a critique of the transaction cost theory. Academy of Management Review, 21(1), 13-47. 
Gilliland, D. I., \& Bello, D. C. (1997). The effect of output controls, process controls, and flexibility on export channel performance. Journal of Marketing, 61, 22-38.

Golembiewski, R. T., \& McConkie, M. (1975). The centrality of interpersonal trust in group processes. In Theories in group process. New York: John Wiley.

Granovetter, M. (1985). Economic action and social structure: the problem of embeddedness. American Journal of Sociology, 91 (3), 481-510.

Grayson, K., \& Ambler, T. (1999). The dark side of long-term relationships in marketing services. Journal of Marketing Research, 36, 132-141.

Grayson, K., Johnson, D., \& Chen, D. F. R. (2008). Is firm trust essential in a trusted environment? How trust in the business context influences customers. Journal of Marketing Research, 241-256.

Gundlach, G. T. (1994). Exchange governance: the role of legal and nonlegal approaches across the exchange process. Journal of Public Policy \& Marketing, 13(2), 246-258.

Gundlach, G. T., \& Achrol, R. S. (1993). Governance in exchange: contract law and its alternatives. Journal of Public Policy \& Marketing, 12, 141-155.

Gundlach, G. T., Achrol, R. S., \& Mentzer, J. T. (1995). The structure of commitment in exchange. Journal of Marketing, 59, 78-92.

Hamel, G. (1991). Competition for competence and inter-partner learning within international strategic alliances. Strategic Management Journal, 12, 83-103.

Heide, J. B. (1994). Inter-organizational governance in marketing channels. Journal of Marketing, 71-85.

Heide, J. B., \& John, G. (1990). Alliances in industrial purchasing: the determinants of joint action in buyer-supplier relationships. Journal of Marketing Research, 27, 24-36.

Heide, J. B., \& John, G. (1992). Do norms matter in marketing relationships? Journal of Marketing, 32-45.

Heide, J. B., Wathne, K. H., \& Rokkan, A. I. (2007). Interfirm monitoring, social contracts and relationship outcomes. Journal of Marketing Research, 44, 425-433.

Ittner, C. D., Larcker, D. F., Nagar, V., \& Rajan, M. V. (1999). Supplier selection, monitoring practices, and firm performance. Journal of Accounting and Public Policy, 18, 253-281.

Jap, S., \& Anderson, E. (2003). Safeguarding interorganizational performance and continuity under ex-post opportunism. Management Science, 49(12), 1684-1701.

Jaworski, B. J. (1988). Toward a theory of marketing control: environmental context, control types, and consequences. Journal of Marketing, 52, 23-39.

Jensen, M. C., \& Meckling, W. H. (1979). Rights and production functions an application to labor-managed firms and codetermination. Journal of Business, 52(4), 469-506.

Jöreskog, K. G., \& Sörbom, D. (1993). LISREL 8, A guide to the program and applications. Chicago: SPSS Inc.

Kramer, R. M. (2009). Rethinking trust. In Harvard business review. $87,68-87$

Kramer, R. M., Brewer, M. B., \& Hanna, B. A. (1996). Collective trust and collective action: The decision to trust as a social decision. In R. M. Kramer \& T. R. Tyler (Eds.), Trust in organizations: Frontiers of theory and research (pp. 357-389). London: Sage.

Krass, A. S. (1985). Verification and trust in arms control. Journal of Peaceful Resolution, 22, 285-288.

Kumar, N., Stern, L. W., \& Achrol, R. S. (1992). Assessing reseller performance from the perspective of the supplier. Journal of Marketing Research, 29, 238-253.

Kumar, N., Scheer, L. K., \& Steenkamp, J.-B. E. M. (1995). The effects of perceived interdependence on dealer attitudes. Journal of Marketing Research, 32, 348-356.
Lazzarini, S. G., Miller, G. J., \& Zenger, T. R. (2004). Order with some law: complementarity versus substitution of formal and informal arrangements. Journal of Law Economics and Organization, 20(2), 261-298.

Lehmann, D. R., \& O'Shaugnessy, J. (1974). Difference in attribute importance for different industrial products. Journal of Marketing, 38, 36-42.

Lewis, D. J., \& Weigert, A. (1985). Trust as a social reality. Social Forces, 63(4), 967-985.

Liker, J. K., \& Choi, T. Y. (2004). Building deep supplier relationships. Harvard Business Review, 82, 104-113.

Lindell, N. K., \& Whitney, D. J. (2001). Accounting for common method variance in cross-sectional research designs. Journal of Applied Psychology, 86, 114-121.

Lippman, S. S., \& McCall, J. J. (2001). Information, economics of. International Encyclopedia of the Social \& Behavioral Sciences, pp. $7480-7486$.

Lorenz, E. H. (1988). Neither friends nor strangers: Informal networks of subcontracting in French industry. In D. Gambetta (Ed.), Trust (pp. 194-210). Oxford: Basil Blackwell.

Luhmann, N. (1979). Trust and power. Chichester: Wiley.

Luhmann, N. (1988). Familiarity, confidence, trust: Problems and alternatives. In D. Gambetta (Ed.), Trust (pp. 94-107). Oxford: Basil Blackwell.

Macaulay, S. (1963). Non-contractual relations in business: a preliminary study. American Sociological Review, 28(1), 55-67.

Macneil, I. R. (1980). The new social contract: An inquiry into modern contractual relations. New Haven and London: Yale University Press.

Magnet, M. (1994). The new golden rule of business. Fortune, 60-64.

Malhotra, N. K., Kim, S. S., \& Patil, A. (2006). Common method variance in IS research: a comparison of alternative approaches and a reanalysis of past research. Management Science, 52, $1865-1883$.

Maltz, E., \& Kohli, A. K. (1996). Market intelligence dissemination across functional boundaries. Journal of Marketing Research, 33, 47-61.

Mayer, R. C., Davis, J. H., \& Schoorman, F. D. (1995). An integrative model of organizational trust. Academy of Management Review, 20(3), 709-734.

Merchant, K. (1990). The effects of financial controls on data manipulation and management myopia. Accounting, Organizations, and Society, 15(4), 297-313.

Mohr, J., Fisher, R. J., \& Nevin, J. R. (1996). Collaborative communication in interfirm relationships: moderating effects of integration and control. Journal of Marketing, 60, 103-115.

Monczka, R. M., Handfield, R. B., Giunipero, L. C., \& Patterson, J. L. (2008). Purchasing and Supply Chain Management. SouthWestern Publishing.

Moorman, C., Deshpande, R., \& Zaltman, G. (1993). Factors affecting trust in market research relationships. Journal of Marketing, 57, 81-101.

Morgan, R. M., \& Hunt, S. D. (1994). The commitment-trust theory of relationship marketing. Journal of Marketing, 58, 20-38.

Murry, J. P., \& Heide, J. B. (1998). Managing promotion program participation within manufacturer-retailer relationships. Journal of Marketing, 62, 58-69.

New York Times (1987). The President in Venice: Economics, contra aid and the gulf, Associated Press, A12, C2.

Noordewier, T., John, G., \& Nevin, J. (1990). Performance outcomes of purchasing arrangements in industrial buyer-vendor relationships. Journal of Marketing, 54, 80-93.

Ouchi, W. G. (1979). A conceptual framework for the design of organizational control mechanisms. Management Science, 25, 833-848. 
Ouchi, W. G. (1980). Markets, bureaucracies and clans. Administrative Science Quarterly, 25, 129-142.

Palmatier, R. W., Scheer, L. K., Evans, K. R., \& Arnold, T. J. (2008). Achieving relationship marketing effectiveness in business-tobusiness exchanges. Journal of the Academy of Marketing Science, 174-190.

Podsakoff, P. M., MacKenzie, S. B., Jeong-Yeon, L., \& Podsakoff, N. (2003). Common method biases in behavioral research: a critical review of the literature and recommended remedies. Journal of Applied Psychology, 88, 615-657.

Poppo, L., \& Zenger, T. (2002). Do formal contracts and relational governance function as substitutes or complements? Strategic Management Journal, 23, 707-726.

Rao, A., \& Monroe, K. B. (1996). Causes and consequences of price premiums. Journal of Business, 69, 511-536.

Rindfleisch, A., \& Heide, J. B. (1997). Transition cost analysis: past, present and future applications. Journal of Marketing, 61, 30-54.

Rindfleisch, A., \& Moorman, C. (2003). Interfirm cooperation and customer orientation. Journal of Marketing Research, 40, 421-436.

Ring, P. S., \& Van de Ven, A. H. (1992). Structuring cooperative relationships between organizations. Strategic Management Journal, 13, 483-498.

Rose, C. M. (1995). Lecture: trust in the mirror of betrayal. Boston University Law Review, 75, 531-558.

Sako, M. (1992). Prices, quality and trust: Inter-firm relations in Britain and Japan. Cambridge: Cambridge University Press.

Sanchez, J. I., \& Brock, P. (1996). Outcomes of perceived discrimination among hispanic employees: is diversity management an luxury or a necessity? Academy of Management Journal, 39, 704-719.

Scanzoni, J. (1979). Social exchange and behavioral interdependence. In R. L. Burgess \& T. L. Huston (Eds.), Social exchange in developing relationships. New York: Academic.

Selnes, F., \& Sallis, J. (2003). Promoting relationship learning. Journal of Marketing, 67, 80-95.
Slater, S. F., \& Atuahene-Gima, K. (2004). Conducting survey research in strategic management. In D. Ketchen \& D. Bergh (Eds.), Research methodology in strategic management (Volume 1, p. 227-250). JAI Press/Elsevier.

Smith, B., \& Barclay, D. W. (1997). The effects of organizational differences and trust on the effectiveness of selling partner relationships. Journal of Marketing, 61, 3-21.

Snidal, D. (1985). The game theory of international politics. World Politics, 38(1), 25-57.

Spence, M. (1973). Job market signaling. Quarterly Journal of Economics, 87(3), 355-374.

Stein, A. A. (1982). Coordination and collaboration: regime in an anarchic world. International Organization, 36(2), 299-324.

Stinchcombe, A. I. (1985). Contracts as hierarchical documents. In A. L. Stinchcombe \& C. Heimer (Eds.), Organization and project management (pp. 121-171). Oslo: Norwegian University Press.

Stump, R. L., \& Heide, J. (1996). Controlling partner opportunism in industrial relationships. Journal of Marketing Research, 33, 431441.

Wang, Q., Kayande, U., \& Jap, S. (2008). The consequences and boundaries of incoherence in buyer-supplier relationships. Working Paper, August.

Wathne, K. H., \& Heide, J. B. (2000). Opportunism in interfirm relationships: forms, outcomes and solutions. Journal of Marketing, 64, 36-51.

Williamson, O. E. (1985). The economic institutions of capitalism. New York: The Free.

Williamson, O. E. (1991). Comparative economic organization: the analysis of discrete structural alternatives. Administrative Science Quarterly, 36, 289-296.

Wilson, E. J. (1994). The relative importance of supplier selection criteria: a review and update. International Journal of Purchasing and Materials Management, 30, 35-41.

Zand, D. E. (1972). Trust and managerial problem solving. Administrative Science Quarterly, 17(2), 229-239. 